\title{
PROPUESTAS TEÓRICAS Y METODOLÓGICAS PARA LA PAZ INTEGRAL INTERCULTURAL EN EDUARDO ANDRÉS SANDOVAL FORERO
}

\author{
Theoretical and methodological proposals for comprehensive \\ intercultural peace.
}

\author{
Ernesto Guerra-García*
}

Recibido:01 de octubre 2020. Aceptado: 02 de diciembre 2020. Publicado: 01 de enero 2021.

Forma de citar este artículo en APA:

Guerra-García, E. (2021, enero-junio). Propuestas teóricas y metodológicas para la paz integral en Eduardo Andrés Sandoval Forero. Revista CoPaLa, Construyendo Paz Latinoamericana 11 (año 6), pp. 1-21. DOI:10.35600.25008870.2021.11.0190, Recuperado desde: http://revistacopala.net/index.php/ojs/article/view/65

\section{Resumen}

La paz integral intercultural de Sandoval-Forero presenta dos genealogías que permiten explicar su propuesta, la teórica y la epistemológica. En la primera se encuentra que la paz es un constructo que se explica, siempre desde una postura no oficial, de descolonización y desde el pensamiento crítico latinoamericano, a partir de una serie de elementos: 1) la interculturalidad desde las relaciones interétnicas, 2) la educación no universalista que parte de pedagogías críticas, 3) La economía, no la del capitalismo neoliberal sino la de las economías sociales y 4) la democracia que considera el empoderamiento pacifista. Se ejemplifica principalmente en el cuestionamiento al indigenismo mexicano y en las propuestas educativas zapatistas, que se desarrollaron con un enfoque para la paz, con justicia, libertad, democracia y dignidad.

En la genealogía epistemológica de la paz integral de Sandoval-Forero se debe partir de una decolonización epistemológica, en el sentido de desprenderse del eurocentrismo científico para basarse en una antropología no oficial ni hegemónica. Se identifica el enfoque cualitativo como base y se hace una propuesta metodológica multimétodo, en la que se combina de manera específica procedimientos desde la etnografía y la investigación acción intercultural, generando así una ruptura - radical con las estructuras rígidas del positivismo.

El artículo describe estas dos genealogías que constituyen la propuesta de paz integral e intercultural de Sandoval-Forero.

\section{Palabras clave}

Paz, Eduardo Andrés Sandoval Forero, interculturalidad, etnografía, investigación acción participativa

\section{Ernesto Guerra-García}

Doctor en Enseñanza Superior por el Centro de Investigación y Docencia en Humanidades del Estado de Morelos (Cuiden). Miembro fundador y Coordinador General de Investigación y Posgrado de la Universidad Autónoma Indígena de México. Pertenece al Sistema Nacional de Investigadores nivel II en ciencias sociales 


\section{Abstract}

Sandoval-Forero's comprehensive intercultural peace presents two genealogies that explain his proposal, the theoretical and the epistemological. In the first one, it is found that peace is a construct that is explained, always from an unofficial position, of decolonization and from Latin American critical thought, based on a series of elements: 1) interculturality from inter-ethnic relations, 2) non-universalist education that starts from critical pedagogies, 3) the economy, not that of neoliberal capitalism but that of social economies and 4) democracy that considers pacifist empowerment. It is exemplified mainly in the Mexican indigenism and in the Zapatista educational proposals, which were developed with a focus on peace, with justice, freedom, democracy and dignity.

In Sandoval-Forero's epistemological genealogy of integral peace, one must start from an epistemological decolonization, in the sense of getting rid of scientific Eurocentrism to be based on an unofficial or hegemonic anthropology. The qualitative approach is identified as the basis and a multi-method methodological proposal is made, in which procedures from ethnography and Participatory Action Research are specifically combined that generate a radical break with the rigid structures of positivism.

\section{Keywords}

Peace, Eduardo Andrés Sandoval Forero, interculturality, ethnography, participatory action research. 


\section{Introducción}

La paz es un constructo que se ha ido desarrollando lentamente hasta nuestros días, cuya explicación pudiera no ser tan sencilla. Los intelectuales que la han abordado han generado obras que han trascendido su tiempo, pues generan aportaciones a la humanidad de carácter inconmensurable. Este es el caso de la obra de Eduardo Andrés Sandoval Forero en relación con la paz, que a través de su trabajo investigativo de más de dos décadas ha podido ofrecer una propuesta innovadora, oportuna y asertiva.

La paz y las condiciones objetivas para vivirla son tan disímiles, menciona Sandoval-Forero (2014), "que dependen de variables económicas, sociales, étnicas, políticas, culturales, religiosas, de género y de relación con el poder" (p. 120).

Al hacer una revisión histórica del concepto de paz, Sandoval-Forero plantea cinco etapas: 1) la primera etapa en el periodo correspondiente entre los años 30 y 60, en la que se aludía a la ausencia de guerra y a la no existencia de la violencia física; 2) la segunda etapa, en la que gracias a los cuestionamientos de Galtung (1998) se genera el concepto de paz positiva y paz negativa, reinterpretada como paz directa, estructural o cultural (Sandoval-Forero, 2012), que se opone a la guerra y a todo tipo de discriminación, como alternativa para reducir la violencia estructural a través de un nivel elevado de justicia; 3) la tercera etapa estuvo marcada por acontecimientos coyunturales de los años 80, que demandaron una mayor participación de los movimientos sociales que le dieron una mayor importancia a la solicitud de paz; 4) la cuarta etapa inicia en la década de los 90, cuando se adopta una perspectiva holística, integral y completa y a la vez se le da gran importancia a la diversidad cultural y del feminismo, como medio para preservar la paz; 5) la quinta etapa es la actual, donde se plantean nuevos temas en relación con los estudios para la paz, tales como el conflicto global, los riesgos mundiales de salud, las violencias trasnacionales, la migración, y las alternativas no hegemónicas, entre otros (Sandoval-Forero, 2012).

Para Sandoval-Forero (2012) la paz no sólo es ausencia de violencia, física, simbólica, cultural, social, económica, política y de género

---que agreden, denigran, excluyen y menosprecian a los otros, a los diferentes, a los extraños, o a los extranjeros...es el reconocimiento y valoración de la vida, la libertad, la justicia, los derechos humanos y las convivencias pacíficas de todos los diversos (p. 21-22). 
Su propuesta de paz es distinta y presenta en nuestros tiempos elementos innovadores; busca que sea duradera e integral con base en la justicia, la libertad y la democracia, difiere completamente de la paz hegemónica, caracterizada por ser etnocéntrica europea y norteamericana, que "mantiene en sus entrañas el pensamiento y la práctica colonizadora, y colonizante, de dominación" (Sandoval-Forero, 2014, p. 120).

El etnocentrismo menciona Sandoval-Forero (2014)

...es toda una ideología, un pensamiento, una teoría, una metodología y una praxis que considera que la cultura occidental es la más avanzada, civilizada, desarrollada, democrática y pacífica, por lo que se adjudica ser el modelo y ejemplo de desarrollo en todos los aspectos de la vida moderna (p. 120).

Pone en evidencia a la cultura de la paz occidental, que se encuentra en prácticamente todas las estructuras sociales y que

---se fundamenta en toda una ideología, un pensamiento, una teoría, una metodología y una praxis que se auto considera la más avanzada, civilizada, desarrollada, democrática y pacífica, por lo que se adjudica ser el modelo y ejemplo de paz y desarrollo en todos los aspectos de la vida moderna (Sandoval-Forero, 2016a, p. 30).

Se trata de la paz etnocéntrica que

...se comporta de manera exclusiva y excluyente de las demás culturas de paz, y sólo acepta aquellas que son afines, las que se enmarcan en sus concepciones y visiones del mundo, y a las que respetan y aceptan los decálogos de paz impuesta. Manifestaciones típicas de hegemonía de la paz etnocéntrica son los discursos, las políticas y los programas que el "mundo desarrollado" le impone o sugiere a los países, gobiernos, políticos o a sectores en "desarrollo" o académicos sobre la paz que tienen que instrumentar. (Sandoval-Forero, 2014, p.121).

La paz hegemónica y etnocéntrica, que corresponde a la cultura de paz occidental, ha generado también dentro de sus estructuras de protección una gran cantidad de instrumentos legales que en su dimensión jurídica aparentan reivindicar los oprimidos, pero que en la práctica presentan candados para modificar el estatus quo de la sociedad.

La propuesta de paz de Sandoval-Forero va más allá de la paz positiva que busca "evitar o destruir todas las expresiones de violencia, la injusticia, el desencuentro, la miseria, la explotación, la incomunicación, la sumisión, las violencias de todo tipo y la desigualdad" (Sandoval-Forero, 2012, p. 21); cuyas herramientas son ...la negociación, el diálogo, la mediación, y la transformación pacífica de los conflictos a partir del diálogo, las normas, las leyes, los derechos humanos, y el reconocimiento de todas las diversidades culturales, étnicas, religiosas, políticas y sociales que permitan el fortalecimiento de las instituciones encargadas de garantizar y promover el bienestar social. (Sandoval-Forero, 2012, p. 21).

Basándose en autores como Galtung (1998), Francisco Muñoz (2010), Vicent Martínez Guzmán (2011), Sandoval-Forero (2014) busca el tratamiento del conflicto por medios no violentos y sobre todo creativos. Ante la paz universalista y homogeneizante, propone un enfoque alternativo para el que construye un marco 
conceptual y metodológico basados en los discursos críticos anticoloniales y de-coloniales, acordes con la diversidad real de culturas y sus condiciones sociales.

Describe la paz como una forma de vida y usando la metáfora del cuerpo humano que funciona como un sistema integral. "Un cuerpo y una mente en armonía estarán en condiciones de paz, siempre y cuando sus entornos o subsistemas también tengan mínimas condiciones de paz” (Sandoval-Forero, 2014, p. 124). Advierte que toma diferentes formas pues cada espacio y tiempo presentan sus propias especificidades y peculiaridades, (SandovalForero, 2012), y propone llegar a una condición utópica y real de paz integral, sustentable y duradera, "revertiendo las condiciones estructurales de la violencia, al igual que las violencias subjetivas construidas, social y culturalmente, en la mente de las personas, así como la eliminación de la violencia armada directa" (Sandoval, 2014, p. 124); con la esperanza de construir “un mundo donde quepan muchos mundos” (Sandoval, 2016b, p. 14).

\section{Metodología}

El análisis que se presenta a continuación parte de la perspectiva del análisis crítico del discurso, los principales elementos ideológicos que han conformado hasta el momento las aportaciones de Sandoval-Forero, que han sido desarrolladas en sus artículos y libros que abordan los estudios para la paz integral. La pregunta principal es ¿Cuáles son esos elementos que conforman las genealogías de ese discurso?

El análisis crítico del discurso (ACD) es un método que de acuerdo con autores como Moreno (2016) y Lima y Rubaii (2016) presenta tres dimensiones respecto del discurso: a) como texto, b) como práctica discursiva y c) como práctica sociocultural. En este trabajo nos enfocaremos a este último inciso. Desde esta perspectiva González-Domínguez y Martell-Gámez (2013) lo definen como un método que

... analiza toda producción del lenguaje, particularmente el verbal (sin dejar de lado el audio-visual que posee también discursividad), con el fin de identificar componentes ideológico-políticos, retóricoafectivos, en todo acto de comunicación y de información. Al mismo tiempo relaciona dichos componentes en uno o varios regímenes discursivos, tanto en la continuidad y discontinuidad de la historia. (p. 164)

Los objetos de análisis del presente artículo se encuentran registrados en artículos científicos y libros que se constituyen históricos por su trascendencia académica, política y social. El ámbito del análisis crítico es microdiscursivo.

Para el análisis se requirió encontrar las reglas de formación, las genealogías, las filiaciones discursivas en un proceso de continuidad-discontinuidad histórica. Lo que significó reconocer los trayectos político, intercultural, educativo y epistemológico de la propuesta de paz integral e intercultural de Sandoval-Forero. Como mencionan 
González-Domínguez y Martell-Gámez "el análisis del discurso, recorre las trayectorias genealógicas (identificación histórica de la emergencia de los discursos) y arqueológicas (las reglas de exclusión y validación de los enunciados de los discursos)" (p. 165).

El poder de acción del contenido del discurso de Sandoval-Forero influyó en la creación de los programas educativos en Estudios para la Paz en la Universidad Autónoma Indígena de México (UAIM) y en la formación del pensamiento crítico de los posgrados donde ha participado. Desde la práctica social, esta formación discursiva se encuentra determinada en el tiempo y en el espacio y se construye de momentos de resignificaciones, rupturas, producción de sentidos en un contexto social específico (Lima y Rubaii, 2016), en las que la gente, a partir de las ideas de Sandoval-Forero, en este caso, ha aplicado recursos materiales y simbólicos. El discurso así opera como "una práctica que constituye sistemáticamente los objetos sobre los que está versando y manifiesta maneras particulares de usar el lenguaje y otras formas simbólicas" (Fairclough , citado por Moreno, 2016, p.133).

Lo que hace particular a este discurso seminal son los constructos usados, su significado y el potencial cambio que se pudiera dar en la sociedad mexicana y latinoamericana. Es necesario aclarar que el ACD permite la multi e interdisciplinariedad. Se tomaron como unidades de análisis las dos genealogías más importantes del discurso de Sandoval-Forero, la primera es su postura teórica en relación con lo que llama paz integral y la segunda que en cierto sentido no se separa de la primera es la metodológica. La idea es llegar a la finalidad socio-política de su discurso. Las categorías y los códigos específicos de análisis emergerán a posteriori de los textos producidos presentados como información empírica (Santander, 2011). No se trata de hacer una mera paráfrasis, se trata de un trabajo en el que se discute, como tela de fondo, el interculturalismo mexicano, el indigenismo y la educación intercultural gubernamental desde arriba.

La producción de Sandoval-Forero deja para la posteridad una huella, pues se encuentra íntimamente ligado y en ruptura total con las violentas estructuras sociales de la actualidad y por ende como menciona Valencia (2011), ha sido usada y reproducida para avalar una ideología.

Aquí se entiende por ideología a "un sistema de creencias políticas: un conjunto de ideas y de valores concernientes al orden político que tienen la función de guiar los comportamientos políticos colectivos" (Bobbio citado por Valencia, 2011: 148).

A continuación, se presentan las dos genealogías principales en la propuesta de paz integral de Sandoval, la teórica y la epistemológica. 


\section{Genealogía teórica de la paz integral}

Para Sandoval la paz es un constructo que se explica, siempre desde una postura crítica y de descolonización, a partir de una serie de elementos socio-antropológicos, la primera de ellas es la interculturalidad vista desde los estudios sobre las relaciones interétnicas, principalmente de los que parten del análisis de la vieja antropología mexicana, donde se denuncia la colonización, la aculturación y el despojo. La segunda es la educación en un sentido pluri-versal, no la oficial que ha partido de una imposición cultural universalista, ni tampoco la que se limita a las aulas, sino aquella que la sociedad promueve, desde abajo, a partir de todas sus instituciones, la que parte de las pedagogías críticas, como la de Freire que a través de la filosofía de la liberación brindó empoderamiento a los sujetos "como actores legítimos de su condición para liberarse de su propia condición de opresión” (Capera, 2017, p. 111). La tercera es la economía, no la del capitalismo ni del neoliberalismo, sino la de las economías alternativas, sociales, comunales e indígenas, más acordes con formas de vida más armónicas con la naturaleza, con el buen vivir, con un entendimiento honesto de la sustentabilidad y de la ecología y la cuarta es el análisis de la democracia, pues no todas sus formas conducen a la paz; en esta última se considera la necesidad de empoderamiento pacifista, entendido este como un saber hacer de sujeto y de la acción colectiva para decidir e incidir en las condiciones de violencia, como estrategia de cambio social no violento .Su propuesta se orienta hacia América Latina y tiene como base, por un lado, sus realidades y por otro las teorías del pensamiento crítico latinoamericano (Sandoval-Forero, 2016a, p. 17).

\section{Contexto indígena}

En México, en un contexto de indiofobia, de importantes movimientos indígenas que desafían la democracia multicultural, el interés por la paz se intensificó ante las negociaciones del ejercito zapatista de liberación nacional EZLN y el gobierno federal. Los diálogos de paz fueron un parteaguas en las políticas públicas indigenistas del país y son un referente en muchos sentidos. Pero el hecho de que el gobierno desatendiera e incumpliera gran parte de los acuerdos, motivó la identificación de una paz imposible (Sandoval-Forero, 2001).

...el autor rescata la dimensión política del proyecto que se construye en los pueblos zapatistas en el sureste de México debido a su postura contrahegemónica y anti-sistémica que manifiestan cotidianamente en su ser, estar y poder de la realidad política mexicana (Capera, 2017, p. 109).

Es por esto que la teoría de paz integral e intercultural de Sandoval se contextualiza en el cuestionamiento al indigenismo mexicano y en las propuestas educativas zapatistas, que se desarrollaron, "al margen de la racionalidad moderna/colonial del Estado mexicano y de la educación intercultural oficial, con un enfoque para la paz, con justicia, libertad, democracia y dignidad" (Sandoval-Forero, 2016a, p. 26). 
Los pueblos zapatistas vienen impulsando de manera sostenible mediante el ejercicio autonómico desde abajo, en sus regiones, a través de sus juntas de buen gobierno, con sistemas de salud, producción, justicia, comunicación y educación propios, con resolución dialogada y pacífica de conflictos a partir de sus historias, sus culturas y sus territorios (Sandoval-Forero, 2016a, p. 28).

Muchos pueblos indígenas en México presentan alternativas que cuestionan las bases epistemológicas de la interculturalidad y de la paz hegemónica a través de procesos endógenos comunitarios. Para la paz se requiere construir formas nuevas de vida para las comunidades, sin el dominio del sistema-mundo moderno colonial.

...y ello se puede comprender en los siete principios del gobernar zapatista: "servir y no servirse", "representar y no suplantar", "construir y no destruir", "obedecer y no mandar", "proponer y no imponer", "convencer y no vencer" y "bajar y no subir". (Sandoval Forero, 2016a , p.35).

\section{La interculturalidad}

Para la construcción de paz integral e intercultural, Sandoval-Forero no parte de las conceptualizaciones impulsadas verticalmente desde el gobierno; influido por el zapatismo mexicano concibe una interculturalidad "otra", la que no se circunscribe en las relaciones asimétricas de poder, donde se encuentran opresores y oprimidos; realiza una crítica a la interculturalidad oficial que busca la subordinación y sometimiento de los pueblos indígenas al dominio gubernamental.

Pero es importante aclarar que no se trata de promover la lucha de los opresores contra los oprimidos, pues esto forma parte de la violencia, sino, en una especie de utopía (en la frontera de lo posible), promover la conciencia en todos los ámbitos y niveles de la sociedad para generar una transformación racional y armónica.

En la interculturalidad que propone Sandoval-Forero (2016a), son insuficientes las categorías básicas como las de "reconocimiento", "respeto", "igualdad", "diálogo de saberes", "libertad de pensamiento", que se utilizan más como un cliché y que con falta de sinceridad se aplica sin que se tenga la intención de que el opresor seda parte del poder que ostenta. "El encuentro cultural acrítico poco incide en las relaciones culturales desiguales" (Sandoval-Forero, 2014: 119).

La interculturalidad para la paz debe ser entendida y asumida en sentido amplio, es decir en sentido sociopolítico, como proyecto que reivindica la otredad de las culturas a partir de la decolonización de la vida cotidiana y del pensamiento dominante y dominado, de manera que se construya una realidad posible de enfrentar en todas sus dimensiones al universalismo, al pensamiento único que atenta contra las culturas indígenas, afro descendientes, populares y todas aquellas que no son afines a la macrocultura moderna mercantil capitalista (Sandoval-Forero, 2016a, p. 36-37). 
La interculturalidad crítica, que propone Sandoval-Forero (2016b), parte de observar en las relaciones entre las culturas la relación entre el nosotros y el otro o los otros, pero propone ir más allá, pues en su giro epistemológico sugiere substituir el concepto actual de relaciones interculturales por el de 'convivialidad' que en el caso mexicano se refiere a modificar en ellas el racismo y la indiofobia (Sandoval-Forero, 2018).

\section{La educación}

Sandoval-Forero (2016a) denuncia que la educación actual se encuentra íntimamente relacionada con las estructuras de dominación, por lo que propone decolonizar el saber.

La tradición homogeneizante y universalista de la cultura occidental...se impone y domina para que todas las otras culturas "dialoguen" y se transformen a imagen y semejanza del modelo de vida "superior" y, de esta manera, puedan vivir en paz. (p.30)

En la educación actual la cultura de paz hegemónica corresponde a la "colonialidad del saber" que tiene una base eurocéntrica, determina cuales epistemologías, teorías y praxis son válidas universalmente, pero invalida otras muchas opciones que pueden cuestionar y poner en riesgo las estructuras sociales.

De aquí que al decir de Vicent Martínez Guzmán, fundador y exdirector de la Cátedra UNESCO de Filosofía para la Paz de la Universitat Jaume I, es necesaria la reconstrucción de las competencias humanas para hacer las paces (París, Comins y Martínez, 2011).

Una nueva educación sería aquella que rompa con todo lo anterior, que realmente contextualice, que no discrimine vía la descalificación, que considere los derechos humanos y los valores culturales para una paz justa.

A la escuela, es a la que le corresponde "aportar a la construcción de la paz integral, sustentable y duradera desde las aulas, en esa convivencia cotidiana de estudiantes, profesores, autoridades y administrativos" (Sandoval-Forero, 2014, p. 125).

Como ejemplo Sandoval-Forero (2016a) pone a los Municipios Autónomos Rebeldes (MAR) que han asumido la tarea de ofertar educación media bajo el lema 'Nueva Educación Autónoma Indígena por la Paz Justa y Digna y por la Humanidad' (p. 32).

De esta manera surge la educación para la paz como un intento de querer cambiar las conductas, "siempre de una forma no violenta y si tolerante" (Sandoval-Forero, 2012: 26), que se basa en una serie de principios: uno de ellos es el oponerse a la uniformidad cultural y "a la imposición de una sola cultura sobre todas las demás" (Sandoval-Forero, 2012: 26). 
Como parte de su proceso de investigación-acción, Sandoval-Forero impulsó en México a partir de 2011, el proyecto educativo para la paz a través de la UAIM, donde generó programas educativos con la intención de preparar especialistas en el área que formaran parte del semillero que se requiere para impulsar la paz en este país. Uno de ellos fue el posgrado en Educación para la Paz y la Convivencia Escolar, que la Secretaría de Educación del Gobierno del Estado de México llevó a cabo, a través de la UAIM, inscrito al Proyecto educativo de la UNESCO en Resolución Internacional de Conflictos y Construcción de Paz del Consorcio de Universidades Cátedra UNESCO.

La relación de la paz integral con la educación es entendida por Sandoval-Forero (2014) como "un subsistema en el que se presentan conflictos, violencias, variedades áulicas y dinámicas de respeto y aplicación de los Derechos Humanos, de tolerancia, reconocimiento a las diversidades y praxis de cultura de paz" (p. 115).

No se trata de un curso o programa adicional, remedial o compensatorio, ni de escuelas especializadas, sino de una ideología profunda sobre la paz que el sistema educativo debe reflejar.

No habla de la educación intercultural gubernamental que simula la paz, la integración y la inclusión a través de la folklorización de los indígenas y de la paz misma y del "maquillaje volátil de gran exhibición, pero intrascendente para la sociedad, los colectivos y las personas” (Sandoval-Forero, 2016b, p. 43).

La educación intercultural gubernamental, en el caso mexicano, ha sido, en términos generales una respuesta del Estado frente al movimiento indígena que ha exigido educación. Sin embargo, el problema ha sido no solo la insuficiencia en la cobertura de las etnorregiones sino el tipo de educación que se ha brindado, pues la curricula en todos los niveles educativos y de manera acentuada en las universidades interculturales oficiales, no existe articulación de conocimientos de las diferentes culturas; en su lugar siguen predominando contenidos, pedagogías y didácticas occidentales orientadas a desindianizar y a aniquilar las culturas, como si formara parte del viejo proyecto vasconcelista (Sandoval-Forero, 2018).

En la praxis, la educación intercultural (gubernamental) tiene que ver directamente con el poder, con una educación al servicio del Estado con autoridades y docentes predominantemente no indígenas y forma parte del neoindigenismo mexicano (Sandoval-Forero, 2018). 
Pregunta Sandoval-Forero (2018): ¿es posible construir una educación intercultural crítica, pacífica sustentada en la justicia social, la libertad, el respeto real a la diferencia, la comunicación, el diálogo y todas las demás relaciones sociales en igualdad de condiciones para todas las culturas? (p. 31). Su propuesta se trata precisamente de dar respuesta a esta interrogante.

La educación intercultural crítica es posible con una "pedagogía horizontal en las relaciones entre educadores y educandos que comparta y valore los distintos saberes, es decir, en procesos de relación y de producción descolonizantes en la escuela" (Sandoval-Forero, 2018, p. 33). Esta pedagogía "consta de tres ámbitos: los fines (el porqué, la finalidad y los objetivos); los medios (el cómo y la metodología) y el curriculum (el qué, los contenidos y la estructura)" (Sandoval-Forero, 2016b, p. 41).

La educación para la paz y la interculturalidad crítica se debe orientar con una ética específica, con valores acordes con la filosofía pertinente y una interculturalidad particular.

Para el autor, el tema de la educación no debe quedarse en la dimensión normativa/ institucional sino llegar al punto de reflexionar sobre un tipo de educación propia (liberadora) que contenga elementos propios de la decolonización y la acción intercultural (Capera, 2017, p. 109).

Para realizar una educación para la paz, se debe pensar en "superar la violencia estructural por medio de la ecología de saberes, las experiencias autónomas y la postura crítica e independiente del Estado en la toma de decisiones comunitarias" (Sandoval-Forero, 2016b, 195).

La ecología de saberes forma parte de un proceso de investigación acción, que consiste en la promoción de diálogos entre el saber científico y humanístico universitario y los saberes que circulan en la sociedad y en las culturas, desde la perspectiva de la no descalificación anticipada (Souza, en Sandoval-Forero, 2018, p. 8). Dentro de estos procesos se destaca la memoria colectiva como un instrumento que genera los aspectos simbólicos, culturales y políticos para la construcción de un tipo de educación para la paz. Sandoval-Forero (2016b) la concibe como un espacio que permite el diálogo profundo entre distintos actores frente a unas circunstancias que han marcado en las comunidades la historia, la vida, la experiencia y la cotidianidad; donde se deconstruye la violencia y se construye y reconstruye la paz.

En general, en esta propuesta, la educación genera espacios para la construcción del empoderamiento desde un tipo particular de pedagogía "crítica y transformadora" que se orienta a que las personas comprendan críticamente su entorno, su mundo y hagan conciencia de su posición como sujetos que se transforman. 


\section{La economía}

En México menciona Sandoval-Forero (2014) existe una violencia estructural sistémica que hace que la condición socio-económica de los habitantes sea una de las más desiguales e injustas del mundo, donde contrastan la gran cantidad de riquezas naturales y medioambientales, con los altos niveles de pobreza de una población con una gran tradición pacífica.

\section{Sandoval-Forero expone}

---la crisis de paz que atraviesa las entidades de la República Mexicana donde señala que los problemas de corrupción, narcopolítica, violación a los derechos humanos, la criminalización de la protesta social y los daños colaterales que ha traído consigo la lógica neoliberal (pobreza, injusticia, violencia) en este territorio. No se puede convertir en el referente que constituya la identidad de México. Para ello, señala que frente a estas circunstancias emerge el otro México, el de la paz, el de la tolerancia, el México de la convivencia, de la hospitalidad internacional, de reconocimiento y respeto a la diversidad étnica y cultural (Capera, 2017, p. 108).

Esta violencia es introducida por la dimensión económica neoliberal que es excluyente y destructora de todas las demás formas económicas, incluyendo las mismas capitalistas. Debido a esto, la paz integral debe partir de la crítica a las estructuras violentas y a todas sus formas de producción de desigualdades, injusticias, de opresión y explotación, generadoras de inequidades y debe vincularse con esquemas económicos alternativos (SandovalForero, 2014).

La lucha por la paz integral menciona Sandoval-Forero (2012)

...no pretende arribar al modelo convencional de desarrollo capitalista, toda vez que este modelo se sustenta en la acumulación irracional de capital, para lo cual requiere de estructuras socioeconómicas violentas manifestadas entre otras realidades, en la explotación intensa de la mano de obra, de la exclusión, de la pobreza y la miseria de millones de seres humanos, situación que se acompaña de la destrucción irrazonable y violenta de la naturaleza y el medio ambiente en general. (p. 30).

Tampoco trata de orientar su discusión hacia las propuestas marxistas de lucha o la confrontación de las clases. Su propuesta se basa en el comunitarismo de los pueblos originarios americanos, en su cosmovisión y modo de vida que fundamentan sus valores en el colectivismo, la comunalidad, el respeto y amor a la naturaleza, el impulso de la espiritualidad, la libertad, la dignidad, la justicia y la paz (Sandoval-Forero, 2014).

Esta idea del comunitarismo ya había sido propuesta por Gandhi, cuando al liberarse la India de Inglaterra se había manifestado en contra de un Estado industrializado y planificador, en su lugar proponía promover aldeas autosustentables de vida comunitaria. 
El desarrollo es visto más como un discurso utilizado por los organismos internacionales para legitimar la intervención de las grandes potencias, de Estados Unidos y de los países europeos en el mundo y con el neoliberalismo dejo de prometer el bienestar en las naciones (Sandoval-Forero, 2016b).

\section{La democracia}

En América Latina, la praxis de la dimensión jurídica y política de los partidos políticos, del sistema electoral, y de todos los condicionantes propios de la formalidad instrumental e institucional se ha establecido como única forma de ejercicio del poder político, que genera prácticas democráticas violentas, siempre en beneficio de muy pocos basado en el perjuicio de muchos. Estas formas, menciona Sandoval-Forero (2012), contrastan con ejemplos indígenas y comunitarios donde la democracia es más directa, pues a través de los usos y costumbres se torna más participativa. Habría que analizar las estructuras democráticas y cómo es que estas favorecen la paz integral intercultural.

Todos los sistemas políticos en América Latina se autodenominan como democráticos, cuando en realidad no cumplen las condiciones ya que presentan una serie de formas de desigualdades económicas, sociales, de apropiación del ejercicio del poder, de género, de etnia, entre otras, que limitan la dimensión política (SandovalForero, 2016b).

En la paz intercultural se busca, además de mitigar estas desigualdades, "transformar la dominación y el poder autoritario, por condiciones necesarias que favorezcan la justicia social, el pensamiento crítico, el ejercicio de la democracia directa, participativa o representativa, así como todas las prácticas comunitarias y colectivas" (Sandoval-Forero, 2016b, p. 41).

Existen muchas definiciones de democracia, pero la que Sandoval ajusta al párrafo anterior es que "es un sistema de gobierno en donde la soberanía radica en el pueblo, y el ejercicio del poder se concreta a través de representantes o de manera directa en la voluntad popular para la toma de decisiones y el ejercicio del poder político" (Sandoval-Forero, 2016b, p. 55). Pero en contextos interculturales como el de América Latina tiene que ver con la igualdad con la que se distribuye el gobierno del pueblo.

Se propone entonces reconstruir el mundo, otro mundo distinto al capitalista, con buen vivir, verdadera paz con justicia y democracia, como dicen los zapatistas: otro mundo posible desde la diversidad, la diferencia y desde abajo" (Sandoval-Forero, 2016b, p. 48). 
Para esto se requiere el empoderamiento de las minorías, pero no "a través de la famosa lógica de las políticas públicas como instrumento de empoderamiento ciudadano" (Capera, 2017, p. 110). Quizá para esto se tendrá que analizar los conceptos de poder, participación, Estado, pobreza, vulnerabilidad, exclusión, inclusión, marginación, entre otros que son referentes obligados (Sandoval-Forero, 2016b, p. 282), para hacer del empoderamiento "una práctica orientada hacia la transformación del ser, estar y poder del sujeto frente a su entorno sociopolítico (comunidad)" (Capera, 2017, p. 11).

\section{Genealogía epistemológica de la paz integral}

Los estudios para la paz integral e intercultural en Sandoval-Forero deben partir de un giro epistemológico, de una decolonización epistemológica, no sólo en el sentido de desprenderse del eurocentrismo científico, sino de dejar de separar al observador y al observado y de asignarles posiciones de dominio y subordinación en el acto científico; es decir, se deben basar en una antropología no oficial, ni hegemónica.

Identifica el enfoque cualitativo como base y hace una propuesta metodológica multimétodo, en la que se combina de manera específica procedimientos desde la teoría fundamentada, la etnografía (en su carácter de microetnografía) y la investigación acción intercultural que pueden ser usados en los procesos endógenos de construcción de paz integral, generando así "una ruptura - radical con las estructuras rígidas del positivismo" (Capera, 2017, p. 108).

El ejemplo ineludible de proceso endógeno para la paz, es el del zapatismo, que es un ...ejercicio autonómico desde abajo, en sus regiones, a través de las juntas de buen gobierno, con sistemas de salud, producción, justicia, comunicación y educación propios, con resolución dialogada y pacífica de conflictos a partir de sus historias, sus culturas y sus territorios (Sandoval-Forero, 2016 ${ }^{\mathbf{a}}$, p.26).

El objetivo de la investigación no sólo es la de generar conocimientos, sino transformar realidades (SandovalForero, 2018). No se trata de la investigación de observación pasiva poco comprometida, sino de "la transformación estructural del poder, de las formas, mecanismos, estructuras, instituciones y prácticas en que se sustentan la explotación, la marginación, la exclusión y dominación de una élite económica y política sobre la mayoría de la población" (Sandoval-Forero, 2016a, p. 28). Para ello, las investigaciones no deben ser individualistas, sino colectivistas, comunalistas. De aquí que se propone la etnografía para los conflictos y la paz (etnopaz) y el método de la investigación acción intercultural (IAI) para que el investigador participe, se involucre y pueda contribuir de forma creativa a la transformación colectiva, a partir de indagar, reflexionar y atender los diferentes tipos de convivencia (violenta y pacífica). De esta manera todas las personas de la comunidad se convierten en coinvestigadores, el investigador externo se integra y forma parte de la comunidad y, sin imponerse, cumple el rol de facilitador de otros conocimientos, de otras experiencias, otras técnicas, otras 
concepciones de la vida, de los conflictos y de la paz, que deben ser consensuadas con los conocimientos y posturas de los actores sociales (Sandoval-Forero, 2018).

Este tipo de investigación desecha los métodos de imposición colonial con patrones centrados en conocimientos eurocentristas a partir de estandarizaciones de supuesta universalidad y neutralidad de las ciencias sociales. En este caso el investigador no dirige, desde una perspectiva decolonial se asume como parte de una comunidad empoderada (Sandoval-Forero, 2018).

Para ello, se tornan emergentes métodos no estandarizados y otras lógicas instrumentales de investigación que se presentan en total ruptura con las imposiciones epistemológicas eurocentristas; pues se sugiere: "simetría epistémica, desjerarquización de los conocimientos, visibilizar y cuestionar las prácticas de dominio y opresión con patrones modernos/coloniales, y construcción del conocimiento con y para los sujetos sociales conocedores, hacedores y pensadores de su propia historia" (Sandoval-Forero, 2018, p. 10).

Para el trabajo de campo etnográfico Sandoval-Forero (2018) sugiere (sin que se tome como dogma) ocho categorías de análisis - no universales ni generalizantes - pensadas en contextos interculturales: actores sociales, geografía, temporalidad, diversidad, diferencia, conflictos, paces y construcciones culturales, que no se abordan de manera separada ni descontextualizada. De aquí que insista en realizar investigaciones situadas, donde se destaca el contexto y se cuestionan los "saberes universales" de la ciencia impuestos por procesos históricos de dominación.

Esta perspectiva epistemológica se amalgama con la interculturalidad crítica que

...invita a la construcción del saber y a la transformación de la realidad en interacción dialógica y simétrica entre investigador/es y sujetos sociales constructores de conocimiento y escenarios de paz...en el sentido de realizar investigación colaborativa hacia la coproducción de conocimientos teóricos y con praxis de inter-aprendizajes e inter-comprensiones de los diversos culturales involucrados en proyectos específicos de construcción de paz, desaprendiendo metodologías y teorías modernas/coloniales que generen saberes nuevos de empatía intercultural crítica que se acompañen con el desaprender de las violencias en procesos vivenciales, superando de manera creativa toda copia de teorías y modelos eurocéntricos (Sandoval-Forero, 2018, p. 14).

La etnografía e investigación acción intercultural para los conflictos y la paz, es un medio para fomentar una inclusión horizontal democrática; es una metodología que supone un proceso interpretativo de lo que se habla, piensa y siente que se conjuga en un sentipensar, que difiere de la supuesta objetividad científica sin emociones, pero con un profundo sentimiento crítico y autocrítico de las prácticas democráticas; es un medio para ir construyendo desde abajo las relaciones equitativas del micropoder en la vida social, para que con la suma de los escenarios locales se construyan ambientes de paz en una sociedad más amplia (Sandoval-Forero, 2018). 
La investigación acción intercultural propone generar relaciones de convivialidad "con base en principios de justicia social, con pensamiento y acción contra toda discriminación, contra el racismo, la indiofaobia, la exclusión, la marginación, la xenofobia, la misoginia, la homofobia, la dominación masculina" (SandovalForero, 2018, p. 35). Su objetivo de investigación "es transformar una realidad con procesos de conocimiento liberador" (Sandoval, 2018, p. 72).

Esta perspectiva epistemológica implica que las teorías y sus métodos de investigación interactúan y se interpelan de acuerdo con el paradigma epistémico post-positivista, en el que es válido utilizar inter-métodos e inter-teorías; también posibilita generar teorías intermedias, entre las teorías generales y las realidades investigadas. Además, esta perspectiva es multidisciplinar, multi-método y multi-técnica (Sandoval-Forero, 2018).

Desde la etnografía se conocen las realidades complejas "inmersas en paces, conflictos, violencias, negociaciones y relaciones interculturales e interétnicas, sin aplicaciones mecánicas y estandarizadas de teorías y métodos que poco aportan a las ciencias sociales y humanas” (Sandoval-Forero, 2018, p. 54).

La metodología etnográfica se plantea al igual que la investigación fundamentada que busca descubrir categorías, conceptos que permitan elaborar nuevas teorías a partir de los mismos datos, de lo obtenido en campo de manera directa. Rompe con la posición positivista de considerar a los actores sociales como objetos de investigación o como simples informantes y al investigador como una persona ajena, con una mirada lejana e indiferente; en su lugar se plantea la coinvestigación descolonizadora y coparticipativa (Sandoval-Forero, 2018).

La etnografía para la paz puede producir, según Sandoval-Forero tres tipos de retórica textual: a) descriptiva, b) explicativa y c) interpretativa.

Todas estas etnografías pueden constituir verdaderos arsenales del conocimiento, y difieren, por los propósitos de la etnografía, la intensidad del trabajo de campo, la manera de clasificar y procesar la información, la codificación de los datos, la elaboración de categorías, la construcción conceptual, y por el análisis e interpretación teórico que se realice de lo investigado (Sandoval-Forero, 2018, p. 61).

De todas las etnografías, menciona Sandoval-Forero (2018), siete aspectos son determinantes para su desarrollo:

1. Precisión de lo que se va a investigar en cuanto a lo temático, lo espacial y lo temporal. 2. Realización de etnografía de campo en coproducción con los actores sociales a partir de referentes empíricos. 3. Selección adecuada de las técnicas, los instrumentos y las herramientas de investigación. 4. Clasificación, codificación y categorización de los datos de campo. 5. Construcción conceptual y teórica de la información de campo. 6. Cimentación de conocimiento teórico y analítico de realidades sobre la paz, la interculturalidad, los conflictos y la democracia. 7. Elaboración del texto etnográfico. (p. 64). 


\section{Síntesis conclusiva}

La paz integral e intercultural de Sandoval-Forero presenta dos genealogías que permiten explicar su propuesta, la teórica y la epistemológica. En la primera se encuentra que la paz es un constructo que se explica siempre desde una postura no oficial, crítica y de descolonización a partir de una serie de elementos: 1) la interculturalidad vista desde los estudios sobre las relaciones interétnicas, 2) la educación no universalista, en un sentido pluri-versal, que parte de pedagogías críticas, 3) La economía, no la del capitalismo ni del neoliberalismo, sino la de las economías alternativas, sociales, comunales e indígenas y 4) la democracia que considera el empoderamiento pacifista. Su propuesta se orienta hacia América Latina y tiene como base, por un lado, sus realidades y por otro las teorías del pensamiento crítico latinoamericano.

La teoría de paz integral e intercultural de Sandoval-Forero se ejemplifica principalmente en el cuestionamiento al indigenismo mexicano y en las propuestas educativas zapatistas, que en un ejercicio autonómico se desarrollaron al margen de la racionalidad moderna/colonial del Estado mexicano, con un enfoque para la paz, con justicia, libertad, democracia y dignidad.

Realiza una crítica a la interculturalidad oficial que busca la subordinación y sometimiento de los pueblos indígenas al dominio gubernamental. Concibe una interculturalidad "otra", la que no se circunscribe en las relaciones asimétricas de poder, que se entiende y se asume en un sentido sociopolítico amplio, como proyecto que reivindica la otredad de las culturas a partir de la decolonización de la vida cotidiana; la que se enfrenta al universalismo, al pensamiento único que atenta contra las culturas indígenas, afro descendientes, populares y todas aquellas que no son afines a la macrocultura moderna mercantil capitalista.

Critica la educación actual, que se encuentra relacionada con las estructuras de dominación donde la tradición homogeneizante y universalista de la cultura occidental se impone para que todas las otras culturas se transformen a imagen y semejanza del modelo de vida "superior"; se trata de una cultura de paz hegemónica que tiene una base eurocéntrica, que determina cuales epistemologías, teorías y praxis son válidas e invalida a otras.

Una nueva educación sería aquella que rompa con todo lo anterior, que realmente contextualice, que considere los derechos humanos y los valores culturales para una paz justa. A la escuela, es a la que le corresponde aportar a la construcción de la paz integral, sustentable y duradera; para esto se requiere cambiar las conductas, entre ellas oponerse a la imposición de una sola cultura sobre todas las demás. No se trata de un curso o programa adicional, remedial o compensatorio, ni de escuelas especializadas, sino de una ideología profunda sobre la paz que el sistema educativo debe reflejar. 
Para Sandoval-Forero la educación intercultural gubernamental simula la paz, la integración y la inclusión a través de la folklorización de los indígenas y de la paz misma y del maquillaje volátil de gran exhibición, pero es intrascendente para la sociedad; ésta ha sido una respuesta del Estado frente al movimiento indígena que ha exigido educación. Sin embargo, en la curricula de todos los niveles educativos no existe articulación de conocimientos de las diferentes culturas; en su lugar siguen predominando contenidos, pedagogías y didácticas occidentales orientadas a desindianizar. En la práctica tiene que ver con el neoindigenismo y directamente con el poder de autoridades y docentes predominantemente no indígenas.

La educación intercultural crítica es posible con una pedagogía horizontal en las relaciones entre educadores y educandos que compartan y valoren los distintos saberes en procesos de relación y de producción descolonizantes en la escuela. Se debe orientar a una educación con una ética específica, con valores acordes con la filosofía de la paz y una interculturalidad particular. A través de ella se debe pensar en superar la violencia estructural por medio de la ecología de saberes, las experiencias autónomas y la postura crítica e independiente del Estado en la toma de decisiones comunitarias.

La ecología de saberes forma parte de un proceso de investigación acción, que consiste en la promoción de diálogos entre el saber científico y humanístico universitario y los saberes que circulan en la sociedad y en las culturas. Dentro de sus procesos se destaca la memoria colectiva como un instrumento que genera los aspectos simbólicos, culturales y políticos para la construcción de un tipo de educación para la paz. Se trata de un espacio que permite el diálogo profundo entre distintos actores frente a unas circunstancias que han marcado en las comunidades la historia, la vida, la experiencia y la cotidianidad; donde se deconstruye la violencia y se construye y reconstruye la paz.

En esta propuesta se generan espacios para la construcción del empoderamiento desde un tipo particular de pedagogía que se orienta a que las personas comprendan críticamente su entorno y hagan conciencia de su posición como sujetos que se transforman.

En México la violencia es introducida a través de la economía neoliberal que es excluyente y destructora de todas las demás formas económicas, incluyendo las mismas capitalistas. Debido a esto, la paz integral debe partir de la crítica de todas sus formas de producción de desigualdades, injusticias, de opresión y explotación, generadoras de inequidades y debe vincularse con esquemas económicos alternativos.

La lucha por la paz integral no pretende arribar al modelo convencional de desarrollo capitalista que se sustenta en la acumulación irracional de capital y que se basa en estructuras socioeconómicas violentas. Tampoco trata 
de orientar su discusión hacia la lucha o la confrontación de las clases. La propuesta se basa en el comunitarismo de los pueblos originarios americanos, en su cosmovisión y modo de vida que fundamentan sus valores en el colectivismo, la comunalidad, el respeto y amor a la naturaleza, el impulso de la espiritualidad, la libertad, la dignidad, la justicia y la paz. El desarrollo es visto más como un discurso utilizado por los organismos internacionales para legitimar la intervención de las grandes potencias en el mundo que con el neoliberalismo dejó de prometer el bienestar en las naciones.

En América Latina el ejercicio del poder político ha generado prácticas democráticas violentas, siempre en beneficio de muy pocos basado en el perjuicio de muchos; se autodenominan como democráticos, cuando en realidad no cumplen las condiciones ya que presentan una serie de formas de desigualdades económicas, sociales, de apropiación del ejercicio del poder, de género, de etnia, entre otras, que limitan la dimensión política. Estas contrastan con ejemplos indígenas y comunitarios donde la democracia es más directa, pues a través de los usos y costumbres se torna más participativa.

En la paz integral e intercultural se busca, además de mitigar estas desigualdades, transformar la dominación y el poder autoritario, por condiciones necesarias que favorezcan la justicia social, el pensamiento crítico, el ejercicio de la democracia directa, participativa o representativa, así como todas las prácticas comunitarias y colectivas.

La democracia en contextos interculturales, como el de América Latina, tiene que ver con la igualdad con la que se distribuye el gobierno del pueblo. Se propone entonces reconstruir el mundo, con buen vivir, verdadera paz con justicia y democracia. Para esto se requiere que el empoderamiento de las minorías sea una práctica orientada hacia la transformación del ser, estar y poder del sujeto frente a su entorno sociopolítico.

En la genealogía epistemológica de la paz integral de Sandoval-Forero se debe partir de un giro epistemológico, de una decolonización epistemológica, en el sentido de desprenderse del eurocentrismo científico para basarse en una antropología no oficial ni hegemónica. Se identifica el enfoque cualitativo como base y se hace una propuesta metodológica multimétodo, en la que se combina de manera específica procedimientos desde la etnogarfía y la investigación acción intercultural que pueden ser usados en los procesos endógenos de construcción de paz integral, generando así una ruptura - radical con las estructuras rígidas del positivismo.

El objetivo de la investigación no sólo es la de generar conocimientos, sino transformar realidades. No se trata de la investigación de observación pasiva poco comprometida, sino de aquella orientada a la transformación estructural del poder, de las formas, mecanismos, estructuras, instituciones y prácticas en que se sustentan la 
explotación, la marginación, la exclusión y dominación de una élite económica y política sobre la mayoría de la población. Para ello, las investigaciones no deben ser individualistas, sino colectivistas, comunalistas. De aquí que se propone la etnografía para los conflictos y la paz (etnopaz) y el método de la IAI para que el investigador participe, se involucre y pueda contribuir de manera creativa a la transformación colectiva, a partir de indagar, reflexionar y atender los diferentes tipos de convivencia (violenta y pacífica). De esta manera todas las personas de la comunidad se convierten en coinvestigadores, el o los investigadores externos se integran y forman parte de la comunidad y, sin imponerse, cumplen el rol de facilitadores de otros conocimientos, de otras experiencias, otras técnicas, otras concepciones de la vida, de los conflictos y de la paz, que deben ser consensuadas con los conocimientos y posturas de los actores sociales.

Este tipo de investigación desecha los métodos de imposición colonial con patrones centrados en conocimientos eurocentristas a partir de estandarizaciones de supuesta universalidad y neutralidad de las ciencias sociales. En este caso el investigador no dirige, desde una perspectiva decolonial se asume como parte de una comunidad empoderada. Para ello, se tornan emergentes métodos no estandarizados y otras lógicas instrumentales de investigación.

Se insiste en realizar investigaciones situadas, donde se destaca el contexto; para el trabajo de campo etnográfico se sugiere (sin que se tome como dogma) ocho categorías de análisis - no universales ni generalizantes pensadas en contextos interculturales: actores sociales, geografía, temporalidad, diversidad, diferencia, conflictos, paces y construcciones culturales, que no se abordan de manera separada ni descontextualizada.

La etnografía e investigación acción intercultural para los conflictos y la paz, es un medio para fomentar una inclusión horizontal democrática; es una metodología que supone un proceso interpretativo de lo que se habla, piensa y siente que se conjuga en un sentipensar, que difiere de la supuesta objetividad científica sin emociones, pero con un profundo sentimiento crítico y autocrítico de las prácticas democráticas; es un medio para ir construyendo desde abajo las relaciones equitativas del micropoder en la vida social.

La investigación acción intercultural propone generar relaciones de convivialidad con base en principios de justicia social, con pensamiento y acción contra toda discriminación. Su objetivo de investigación es transformar una realidad con procesos de conocimiento liberador. Esto implica que las teorías y sus métodos de investigación interactúan y se interpelan de acuerdo con el paradigma epistémico post-positivista, en el que es válido utilizar inter-métodos e inter-teorías; también posibilita generar teorías intermedias, entre las teorías generales y las realidades investigadas. Además, esta perspectiva es multidisciplinar, multi-método y multitécnica. 
La metodología etnográfica se plantea al igual que la investigación fundamentada que busca descubrir categorías, conceptos que permitan elaborar nuevas teorías a partir de los mismos datos, de lo obtenido en campo de manera directa. Rompe con la posición positivista de considerar a los actores sociales como objetos de investigación o como simples informantes y al investigador como una persona ajena, con una mirada lejana e indiferente; en su lugar se plantea la coinvestigación descolonizadora y coparticipativa.

\section{Referencias bibliográficas}

Acuña, A., Bernal, P., y Martinez, A. (2009). Análisis de experiencias de educación para la paz en américa latina. (Tesis de maestría) Pontificia universidad javeriana, Bogotá, Colombia.

Adams, D. (2016). Cultura de paz y algunos consejos para Colombia. En González, L. (Ed.), Pensar en educación para la paz. Apuestas del encuentro nacional de educación para la paz. Bogotá, Colombia. Agencia del gobierno de estados unidos para el desarrollo internacional USAID; organización internacional para las migraciones OIM.

Aguirre león, CA. (2016). Educación para la paz y políticas educativas en américa latina. Revista inclusión y desarrollo. No. (1) vol. (2).

Barroso, J. (Ed.). (2006). A regulação das políticas públicas de educação: espaços, dinâmicas e atores. Lisboa, Portugal; Educa.

Cabezudo, A. (2012). Educación para la paz: una construcción de la memoria, la verdad y la justicia. Desafio pedagógico de nuestro tiempo em américa latina. Ciências sociais Unisinos. no. (2) vol. (48)

Comins Mingol, I. (2003). La ética del cuidado como educación para la paz. (Tesis de doctorado) Universitat Jaume I, Castellón, España.

Gutierrez, f. (2016). El poema punk de los sin futuro. The lighting mind. Recuperado de: https://www.thelightingmind.com/el-poema-punk-de-los-sin-futuro/

Klainer, R. (2000). Estudio para el análisis de experiencias de educación en derechos humanos en argentina. En R. Cuéllar (Ed.) Experiencias de educación en derechos humanos en américa Latina. San José, Costa Rica: Lihssa.

Magendzo, A. (2008). Pensamiento e ideas-fuerza de la educación en derechos humanos en Iberoamérica. Catedra Unesco, y Fundación Ideas. Recuperado de: http://unescopaz.uprrp.edu/documentos/ideasfuerza.pdf.

Morales, M., y López, V. (2019). Políticas de convivencia escolar em américa latina: cuatro perspectivas de comprensión y acción. Archivos analíticos de políticas educativas. Tempe, Arizona, Estados Unidos.

Novaes, R. (2011). Os direitos da juventude no panorama das políticas públicas no brasil: conquistas e controvérsias. Secretaria da juventude, Unesco. octubre.

ONU, (1999). Declaración y programa de acción sobre una cultura de paz, resolución 53/243, 6 de 
Pabis, NA., y De Souza Martins, M. (2014). Educação e diversidade cultural. Proposta curricular de pedagogia. Paraná: Unicentro.

Tuvilla, J. (2004). Educación en Derechos Humanos. En M. López Martínez (Dir.) (2004) Enciclopedia de Paz y Conflicto. Granada: Editorial Universidad de Granada,

Unesco, (1997). Uma “Cultura de paz” para América Latina. Fuentes Unesco no. (86).

Unesco, (2000). Programa de Acción sobre una Cultura de Paz. Cultura de Paz, no. (22).

Zaritzky, G (1999). La formación para la convivencia y los derechos del niño. En Ospina, H y otros (Comp.) Educación para la Paz: Una pedagogía para consolidar la democracia social y participativa. Bogotá, Colombia. Cooperativa Editorial Magisterio Cargraphics. 